Prepared in cooperation with the

National Oceanic and Atmospheric Administration, National Weather Service

\title{
Documentation of a Restart Option for the U.S. Geological Survey Coupled Groundwater and Surface-Water Flow (GSFLOW) Model
}

Chapter 3 of

Section D, Groundwater/Surface-Water Interactions

Book 6, Modeling Techniques

Techniques and Methods 6-D3 



\section{Documentation of a Restart Option for the U.S. Geological Survey Coupled Groundwater and Surface-Water Flow (GSFLOW) Model}

By R. Steven Regan, Richard G. Niswonger, Steven L. Markstrom, and

Paul M. Barlow

Chapter 3 of

Section D, Groundwater/Surface-Water Interactions

Book 6, Modeling Techniques

Prepared in cooperation with the

National Oceanic and Atmospheric Administration, National Weather Service

Techniques and Methods 6-D3 


\title{
U.S. Department of the Interior SALLY JEWELL, Secretary
}

\section{U.S. Geological Survey \\ Suzette M. Kimball, Acting Director}

\author{
U.S. Geological Survey, Reston, Virginia: 2015
}

For more information on the USGS - the Federal source for science about the Earth, its natural and living resources, natural hazards, and the environment—visit http://www.usgs.gov or call 1-888-ASK-USGS.

For an overview of USGS information products, including maps, imagery, and publications, visit http://www.usgs.gov/pubprod/.

Any use of trade, firm, or product names is for descriptive purposes only and does not imply endorsement by the U.S. Government.

Although this information product, for the most part, is in the public domain, it also may contain copyrighted materials as noted in the text. Permission to reproduce copyrighted items must be secured from the copyright owner.

Although this software has been developed and used by the USGS, no warranty, expressed or implied, is made by the USGS or the U.S. Government as to its accuracy and functionality and related material, nor shall the fact of distribution constitute any such warranty, and no responsibility is assumed by the USGS in connection therewith.

Suggested citation:

Regan, R.S., Niswonger, R.G., Markstrom, S.L., and Barlow, P.M., 2015, Documentation of a restart option for the U.S. Geological Survey coupled groundwater and surface-water flow (GSFLOW) model: U.S. Geological Survey Techniques and Methods, book 6, chap. D3, 19 p., http://dx.doi.org/10.3133/tm6D3.

ISSN 2328-7055 (online) 


\section{Preface}

This report describes a new restart option for the U.S. Geological Survey (USGS) coupled Groundwater and Surface-Water Flow (GSFLOW) numerical, hydrologic simulation code, which is an integration of the USGS Precipitation-Runoff Modeling System (PRMS) and Modular Groundwater-Flow (MODFLOW) simulation codes. The restart option can be a convenient method to start and stop simulations at selected times, which may be useful for simulating short-term streamflow forecasts, for calibration, or for other model analyses that require repeated simulations. With this new capability, all results at the end of one simulation required to initiate a subsequent simulation can be written to and read from antecedent (or initial) conditions files. The report also describes two example applications. The software has been tested on several different computer systems and configurations using several applications. Future applications, however, might reveal errors that were not detected during testing. Users are requested to notify the U.S. Geological Survey of any errors found in this report or the code and submit questions using the MoWS contact form link at the bottom of the Web page at http://wwwbrr.cr.usgs.gov/projects/SW_MoWS/.GSFLOW and other water-related software are available at http://water.usgs.gov/software/. 


\section{Acknowledgments}

This report was prepared in cooperation with the National Oceanic and Atmospheric Administration, National Weather Service as part of the Integrated Water Resources Science and Services partnership. The authors thank Edward Clark of the National Weather Service for input and guidance throughout the development of the restart option. We also thank our U.S. Geological Survey colleagues Anna N. Glover, Rheannon M. Hart, Stephanee Walker, and Linda R. Woolfenden for their helpful review comments on an earlier draft of this report. 


\section{Contents}

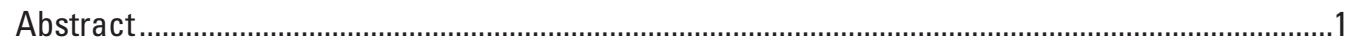

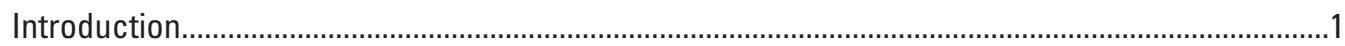

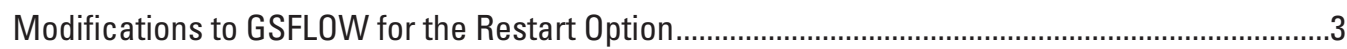

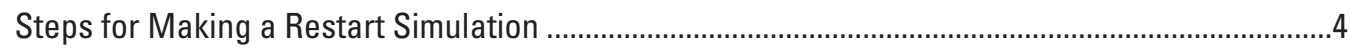

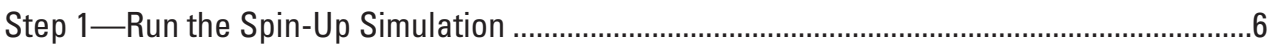

Step 2-Run the Restart Simulation ..................................................................................

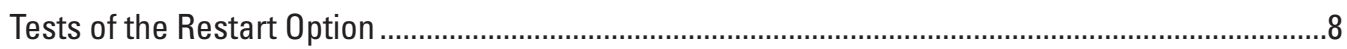

Sagehen Creek Watershed Model.....................................................................................

Lake Tahoe Watershed Model............................................................................................

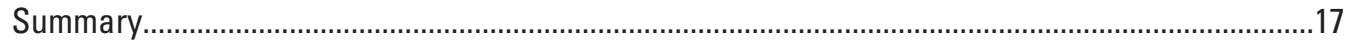

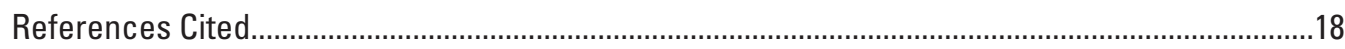

\section{Figures}

1. Schematic illustration showing many of the hydrologic processes simulated by the coupled groundwater and surface-water flow model GSFLOW ......................................2

2. Schematic illustration showing approach used to test the GSFLOW restart option. A, Continuous simulation mode and B, restart simulation mode.....................................8

3. Map showing model boundary of the Sagehen Creek watershed near Truckee, California

4. Part of the Control File for the first (or spin-up) hindcast simulation for tests with the GSFLOW model of the Sagehen Creek watershed near Truckee, California.............11

5. MODFLOW Name Files for two hindcast simulations with the GSFLOW model of the Sagehen Creek watershed near Truckee, California.

6. Part of the GSFLOW Control File for the second hindcast simulation for tests with the GSFLOW model of the Sagehen Creek watershed near Truckee, California.............13

7. Graphs showing results for the continuous and hindcast simulations for tests with the GSFLOW model of the Sagehen Creek watershed near Truckee, California. ...........14

8. Map showing area of the GSFLOW model of the Lake Tahoe watershed on the border between California and Nevada. A, Lake Tahoe watershed and B, surface and groundwater discretization used for GSFLOW model

9. Graphs showing results for the continuous and hindcast simulations for tests with the GSFLOW model of the Lake Tahoe watershed on the border between California and Nevada. 


\section{Conversion Factors}

International System of Units to Inch/Pound

\begin{tabular}{lcl}
\hline \multicolumn{1}{c}{ Multiply } & \multicolumn{1}{c}{ By } & \multicolumn{1}{c}{ To obtain } \\
\hline & Length & \\
\hline meter $(\mathrm{m})$ & 3.281 & foot $(\mathrm{ft})$ \\
kilometer $(\mathrm{km})$ & 0.6214 & mile $(\mathrm{mi})$ \\
\hline & Volume & \\
\hline cubic meter $\left(\mathrm{m}^{3}\right)$ & 35.31 & cubic foot $\left(\mathrm{ft}^{3}\right)$ \\
\hline & Flow rate & \\
\hline cubic meter per second $\left(\mathrm{m}^{3} / \mathrm{s}\right)$ & 35.31 & cubic foot per second $\left(\mathrm{ft}^{3} / \mathrm{s}\right)$ \\
\hline
\end{tabular}

Vertical coordinate information is referenced to the North American Vertical Datum of 1988 (NAVD 88).

Horizontal coordinate information is referenced to the North American Datum of 1983 (NAD 83) or World Geodetic Coordinate System of 1984 (WGS 84).

Altitude, as used in this report, refers to distance above the vertical datum.

\section{Supplemental Information}

The following font styles are used in this report in reference to components of the GSFLOW software:

- PRMS and GSFLOW modules and user-specified input values (in figures 4-6) are identified in Courier New font.

- PRMS and GSFLOW input parameters and MODFLOW input variables are identified in Times New Roman bold font.

GSFLOW has three simulation modes: MODFLOW-only, PRMS-only, and coupled. The coupled mode is referred to as GSFLOW. Variables that are calculated flow rates are referred to as fluxes. Variables that are calculated water-content storages, groundwater heads, and altitudes are referred to as states. 


\section{Abbreviations}

$\begin{array}{ll}\text { BAS } & \text { Basic Package } \\ \text { CBH } & \text { Climate-by-HRU file } \\ \text { ESP } & \text { extended streamflow prediction } \\ \text { GSFLOW } & \text { Groundwater and Surface-Water Flow } \\ \text { HRU } & \text { hydrologic response unit } \\ \text { IRED } & \text { Restart Read file } \\ \text { IWRT } & \text { Restart Write file } \\ \text { LAK7 } & \text { Lake Package version 7 } \\ \text { MNW2 } & \text { Multi-Node Well Package version 2 } \\ \text { MODFLOW } & \text { Modular Groundwater-Flow Model } \\ \text { MODFLOW-NWT } & \text { Newton formulation for the Modular Groundwater-Flow Model } \\ \text { NWS } & \text { National Weather Service } \\ \text { PRMS } & \text { Precipitation-Runoff Modeling System } \\ \text { RFC } & \text { River Forecasting Center } \\ \text { USGS } & \text { U.S. Geological Survey }\end{array}$





\title{
Documentation of a Restart Option for the U.S. Geological Survey Coupled Groundwater and Surface-Water Flow (GSFLOW) Model
}

\author{
By R. Steven Regan, Richard G. Niswonger, Steven L. Markstrom, and Paul M. Barlow
}

\section{Abstract}

A new option to write and read antecedent conditions (also referred to as initial conditions) has been developed for the U.S. Geological Survey (USGS) Groundwater and Surface-Water Flow (GSFLOW) numerical, hydrologic simulation code. GSFLOW is an integration of the USGS Precipitation-Runoff Modeling System (PRMS) and USGS Modular Groundwater-Flow Model (MODFLOW), and provides three simulation modes: MODFLOW-only, PRMSonly, and GSFLOW (or coupled). The new capability, referred to as the restart option, can be used for all three simulation modes, such that the results from a pair (or set) of spin-up and restart simulations are nearly identical to results produced from a continuous simulation for the same time period. The restart option writes all results to files at the end of a spin-up simulation that are required to initialize a subsequent restart simulation. Previous versions of GSFLOW have had some capability to save model results for use as antecedent conditions in subsequent simulations; however, the existing capabilities were not comprehensive or easy to use. The new restart option supersedes the previous methods. The restart option was developed in collaboration with the National Oceanic and Atmospheric Administration, National Weather Service as part of the Integrated Water Resources Science and Services Partnership. The primary focus for the development of the restart option was to support medium-range (7- to 14-day) forecasts of low streamflow conditions made by the National Weather Service for critical water-supply basins in which groundwater plays an important role.

The spin-up simulation should be run for a sufficient length of time necessary to establish antecedent conditions throughout a model domain. Each GSFLOW application can require different lengths of time to account for the hydrologic stresses to propagate through a coupled groundwater and surface-water system. Typically, groundwater hydrologic processes require many years to come into equilibrium with dynamic climate and other forcing (or stress) data, such as precipitation and well pumping, whereas runoff-dominated surface-water processes respond relatively quickly. Use of a spin-up simulation can substantially reduce execution-time requirements for applications where the time period of interest is small compared to the time for hydrologic memory; thus, use of the restart option can be an efficient strategy for forecast and calibration simulations that require multiple simulations starting from the same day.

\section{Introduction}

Surface-water and groundwater resources often are managed together to sustain water supplies for human populations and ecological functioning. In an effort to improve simulation of hydrologic processes important for water-resources management, the U.S. Geological Survey (USGS) developed the coupled Groundwater and Surface-Water Flow model (GSFLOW; Markstrom and others, 2008). GSFLOW is designed to simulate hydrologic response for a wide range of climatic conditions, including wet periods that produce large surface and subsurface flow rates to periods of drought when surface flow is provided primarily by groundwater discharge to streams, lakes, and springs. GSFLOW is the integration of two previously developed numerical, hydrologic simulation codes - the USGS Precipitation-Runoff Modeling System (PRMS) and the USGS Modular Groundwater-Flow Model (MODFLOW). Flexibility for many types of model applications is provided by the capability of GSFLOW to run in MODFLOW-only, PRMS-only, and GSFLOW (or coupled) simulation modes. GSFLOW provides the capability to simulate hydrologic feedback among terrestrial, surface-water, soil, and groundwater processes that affect the timing and rates of evapotranspiration, snowmelt, surface runoff, interflow, recharge, and groundwater discharge to streams and lakes in response to dynamic climate and other forcing stresses such as groundwater pumping. Many of the hydrologic processes simulated by GSFLOW are schematically illustrated in figure 1. 


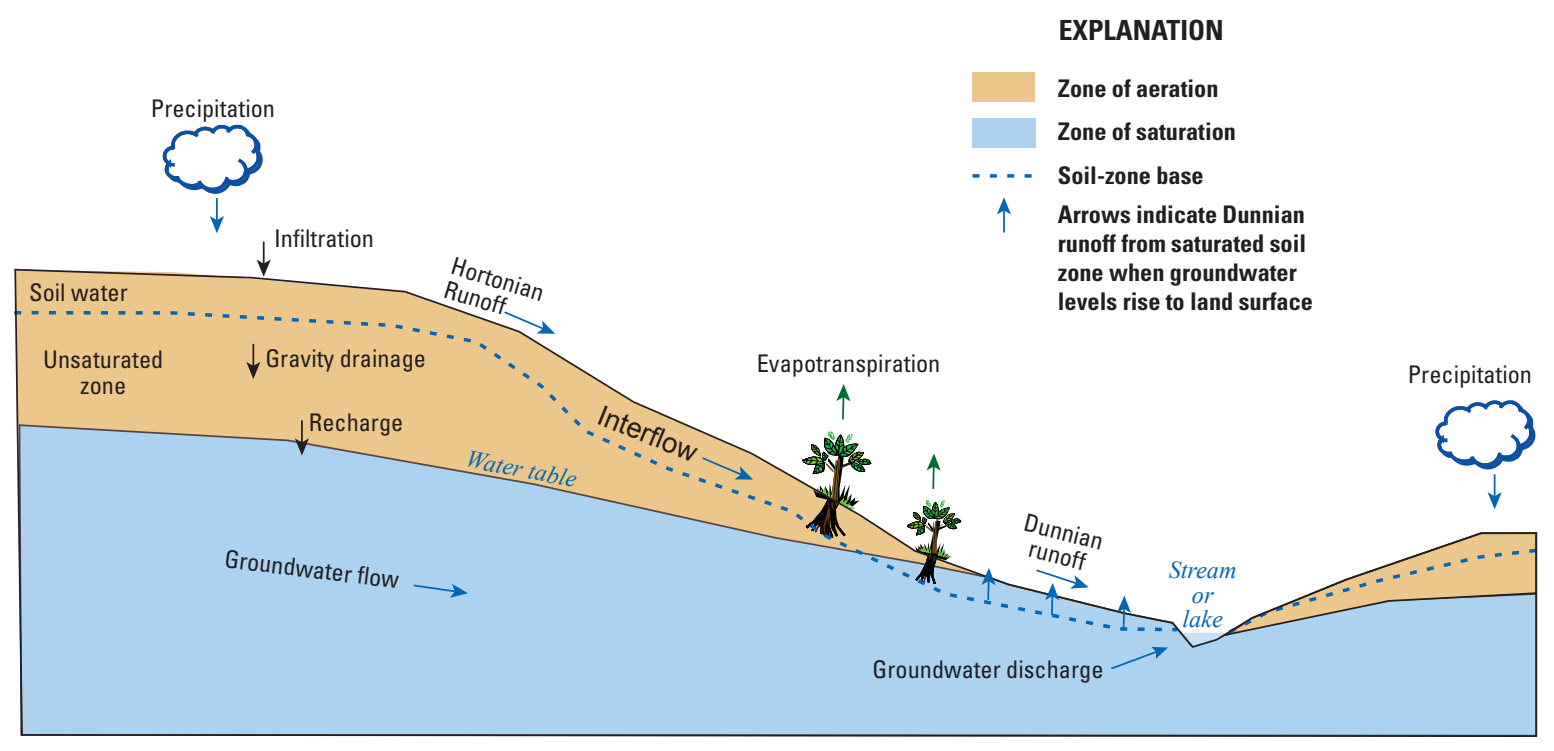

Figure 1. Many of the hydrologic processes simulated by the coupled Groundwater and Surface-Water Flow (GSFLOW) model.

Due to long-term hydrologic memory caused by variable climatic conditions, land-use changes, and groundwater development, there often is a need to save the results (hydrologic conditions) of a particular simulation for later use as antecedent conditions (also referred to as initial conditions) in subsequent simulations. For example, the National Oceanic and Atmospheric Administration, National Weather Service (NWS) River Forecasting Centers (RFCs) use numerical models to forecast streamflow conditions for individual watersheds by use of a set (or ensemble) of alternative forecasted climate conditions. Each simulation (or forecast) begins from a common starting date. This procedure is referred to as extended streamflow prediction (ESP). The California-Nevada RFC first used the ESP procedure in the 1970s and it has been included in the NWS River Forecast System since 1984 (Day, 1985). To reduce the time required to execute each forecast, model results generated from a simulation for a specified preceding time period (referred to as a spin-up simulation) are used as antecedent conditions for each forecast (referred to as a restart simulation). The need to reduce the execution time for each forecast is particularly important for GSFLOW applications for large areas with substantial groundwater and surface-water interactions for which spin-up simulations can require a time period of a decade or more to establish antecedent conditions. In some cases, the time required to run a spin-up simulation can take several hours to days, whereas the time required to run each forecast can take only minutes to hours. Thus, avoiding the need to make spin-up simulations for each forecast provides a substantial savings of computational resources.

Typically, surface-water, shallow-subsurface, and groundwater processes respond on substantially different temporal scales to changes in hydrologic stresses. For example, surfacewater processes can respond relatively quickly, shallowsubsurface processes less quickly, and groundwater processes more slowly to reach an equilibrium state to dynamic stresses such as changing climate, land use, and groundwater and surface-water development. Many years of simulation may be necessary before the groundwater-flow system fully equilibrates to these stresses. Calculating and saving antecedent conditions that represent the equilibrium state and hydrologic memory of past climatic and water-use conditions also can be convenient for calibration purposes. Antecedent conditions are calculated once in the spin-up simulation and then used as input to the tens to thousands of simulations required to adequately calibrate a model.

Previous versions of GSFLOW have had some capabilities to save results from a simulation for use as antecedent conditions in subsequent restart simulations; however, the existing capabilities were not comprehensive or easy to use and did not eliminate the need for a spin-up simulation for MODFLOW-only and GSFLOW simulation modes. Previous versions did provide a restart capability for PRMS-only simulation mode, with PRMS results available for input to subsequent PRMS-only simulations (Markstrom and others, 2008, p. 136, 139); however, the combination of PRMS-only spin-up and restart simulations did not consistently simulate seamless restart simulations in which the restart simulation produced the same results as a continuous simulation. There was no capability to produce seamless restart simulations for MODFLOW-only or GSFLOW simulation modes.

To address these limitations, the USGS and NWS began a collaborative project in 2013 as part of the Integrated Water 
Resources Science and Services partnership to add a new restart option to GSFLOW. This option provides the capability to save results from the spin-up simulation that are required as antecedent conditions for subsequent restart simulations, such that the results throughout a series of restart simulations are nearly identical to those produced from a continuous simulation for the same time period. This new option for GSFLOW can be used for the three simulation modes (MODFLOWonly, PRMS-only, and GSFLOW), and supersedes the restart options in previous versions of GSFLOW. The primary focus for this development was to support medium-range (7- to 14-day) forecasts of low streamflow conditions made by the NWS for critical water-supply basins in which groundwater plays an important role. Additionally, the restart option will support any modeling activity that requires repeated simulations that use a common set of antecedent conditions, such as ensemble simulations, model calibration, and sensitivity analysis. Throughout this report, the simulation that generates the antecedent conditions required for use in subsequent simulations is referred to as the spin-up simulation, whereas simulations that use those antecedent conditions are referred to as restart simulations.

The remainder of this report describes modifications that were made to the GSFLOW code to support the restart option, steps necessary to use the restart option, and sample applications to demonstrate that the restart option is working as intended. Detailed background information on GSFLOW is provided by Markstrom and others (2008). Additional information about the code, as well as the PRMS and MODFLOW codes on which GSFLOW is based, is provided by Leavesley and others (1983, 2005), Harbaugh (2005), Niswonger and Prudic (2005), Niswonger and others (2006, 2011), Henson and others (2013), and Markstrom and others (2015), as well as supplemental notes provided with each release of GSFLOW (http://water.usgs.gov/ogw/gsflow/). It is assumed that the reader is familiar with the theory provided in these documents and use of GSFLOW, PRMS, and MODFLOW.

\section{Modifications to GSFLOW for the Restart Option}

The purpose of the new restart option is to provide a method to use the results of one simulation to initiate any number of subsequent restart simulations. When input values and computation options are identical, results for a sequential series of spin-up and restart simulations are nearly identical to results produced from a continuous simulation for the same time period. Development of the restart option was accomplished by modifying existing source code and by adding new source code to write simulation results to unformatted, binary files from a spin-up simulation that are then read as antecedent conditions for a subsequent restart simulation. Some PRMS and GSFLOW modules and MODFLOW packages did not need to be modified because variables and computations are based on variables calculated in other modules or packages and (or) are based on parameter values that are read at the start of spin-up and restart simulations.

The PRMS and MODFLOW codes that underlie GSFLOW have had some capability to save calculated results at the end of a simulation and to read those results as antecedent conditions for restart simulations. Options for writing and reading antecedent conditions with previous versions of GSFLOW are described for PRMS by Leavesley and others (1983, p. 72-75; 2005, p. 15), for MODFLOW by Harbaugh (2005), and for GSFLOW in PRMS-only simulation mode by Markstrom and others $(2008$, p. 136, 139). The new restart option supersedes the previous methods. The GSFLOW version documented in this report is based on MODFLOW-NWT, which is a Newton formulation for MODFLOW (Niswonger and others, 2011).

Both the PRMS and MODFLOW codes write and read files for the new restart option. These files are written on the last day (time step) of a spin-up simulation and contain all results required to initialize a restart simulation. The PRMS Initial Conditions File contains calculated results for the PRMS and GSFLOW modules. PRMS Initial Conditions Files written by the previous restart method are not compatible with the new restart option, even though the same control parameters are used to specify the files. The MODFLOW Restart Write File contains calculated results for the MODFLOW packages. The calculated results in the PRMS and MODFLOW files are used as antecedent conditions for the first day of the restart simulation; that is, the day following the last day (time step) of the spin-up simulation. Example results written to PRMS Initial Condition Files are snow-pack depths, soilwater storage, and evapotranspiration rates, and for PRMSonly simulation mode, groundwater and streamflow rates. Example results written to MODFLOW Restart Write Files include groundwater heads, unsaturated-zone water contents, streamflow, lake stages, and water levels in multiaquifer wells.

Antecedent conditions for the restart option are read prior to computations for the first day of a restart simulation. Antecedent-conditions files are written at the conclusion of a spin-up simulation. For MODFLOW-only and GSFLOW simulation modes, the MODFLOW input files are read up to the stress period and time step for the start time of the restart simulation, which is specified by use of control parameter start_time in the Control File, prior to computation of the first day of a restart simulation. A new control parameter (modflow_time_zero), specified in the Control File, was added to define the date of the first time step (TS1) of the first transient stress period (SP1) specified in the MODFLOW Discretization File. If an initial steady-state simulation has been specified in the Discretization File, that initial simulation will be ignored and not executed for restart simulations. Before the implementation of the restart option, GSFLOW assumed that the first time step of the first transient stress period corresponded to the date specified by control parameter start_time; however, for restart simulations, start_time may be specified to a date later than SP1 and TS1 and, therefore, the date of SP1 and TS1 
must be specified to allow GSFLOW to skip forward through each MODFLOW input file during the restart simulation to the correct stress-period information. The date specified for modflow_time_zero cannot be later than that specified for start_time; GSFLOW will issue an error message and stop execution if modflow_time_zero is specified to be a date later than start_time. If modflow_time_zero is not specified, the value is set to start_time. GSFLOW calculates the date corresponding to the beginning of each specified stress period and time step on the basis of the total length of each stress period specified in the MODFLOW Discretization File for a restart simulation. Examples of the use of control parameters start_time and modflow_time_zero are provided in the discussion of the test cases. As in previous versions of GSFLOW, for PRMS-only or GSFLOW simulation modes, the required PRMS Data File(s) and optional PRMS Climate-by-HRU (CBH) Files are read until the date specified by start_time for the restart simulation.

The PRMS and GSFLOW modules that were modified each have a new routine that writes to and reads from a PRMS Initial Conditions File. These modules write to a PRMS Initial Conditions File for PRMS-only and GSFLOW mode restart simulations when control parameter save_vars_to_file is specified equal to 1 ; the pathname of this file is specified by control parameter var_save_file. When control parameter save_vars_to_file is specified equal to 0 , the value of control parameter var_save_file is ignored. The modules read from an Initial Conditions File for PRMS-only and GSFLOW mode restart simulations when control parameter init_vars_from_file is specified equal to 1 ; the pathname of this file is specified by control parameter var_init_file. When control parameter init_vars_from_file is specified equal to 0 , the value of control parameter var_init_file is ignored. Thus, there can be two Initial Conditions Files accessed during a PRMS-only or GSFLOW simulation, one that is read to define the antecedent conditions for a restart simulation and a second that is used to save antecedent conditions at the end of the simulation. Thus, a single simulation can be both a restart and a spin-up simulation.

Two new file types were added to MODFLOW to read and write MODFLOW-related antecedent conditions for a MODFLOW-only or GSFLOW restart simulation. These are the Restart Write File (file type IWRT) and the Restart Read File (file type IRED). MODFLOW-related antecedent conditions are written to the Restart Write File if a file of type IWRT is specified in the MODFLOW Name File and control parameter save_vars_to_file is specified equal to 1. MODFLOW-related antecedent conditions are read from the Restart Read File if a file of type IRED is specified in the MODFLOW Name File and control parameter init_vars_from_file is specified equal to 1 in the Control File. Thus, there can be two MODFLOW antecedent-conditions files accessed during a GSFLOW or MODFLOW-only restart simulation, one that is read to define the antecedent conditions at the start of a restart simulation and another that is used to save antecedent conditions at the end of the simulation. When control parameter init_vars_from_file is specified equal to 0 , the value of control parameter var_init_file and IRED are ignored, if specified.

\section{Steps for Making a Restart Simulation}

There are two primary steps for using the restart option: (1) execute a spin-up simulation to compute and save antecedent conditions for a subsequent restart simulation, and (2) execute the restart simulation. Results from any length simulation written to PRMS and MODFLOW antecedent-conditions files can be used as the antecedent conditions for restart simulations. The user specifies a time period for the spin-up simulation that is of sufficient length to account for the hydrologic memory throughout the model domain such that the simulation has come into equilibrium with the specified climate and other forcing conditions. Typically, the spin-up simulation used to generate antecedent-conditions files has been calibrated and verified for historical conditions.

The spin-up and restart simulations are activated by specifying appropriate input values in the Control File and MODFLOW Name File. The Control File is used to specify several control-parameter values related to a GSFLOW simulation, including simulation mode (that is, MODFLOWonly, PRMS-only, and GSFLOW), simulation starting and ending times, PRMS module selections, input and output file names and options, and PRMS Initial Condition File names and options (Markstrom and others, 2008, table A1-1, p. 134-137). The Name File is used to specify the set of active MODFLOW packages, file types (including the new IRED and IWRT file types), Fortran unit numbers, and pathnames of the input and output files used in MODFLOW-only and GSFLOW simulation modes (Markstrom and others, 2008, p. 177-178). The Control File and Name File for the spin-up simulation will differ from those for the restart simulation because the options used to specify the reading and writing of antecedentconditions files for the spin-up simulation will be different from those for the restart simulation.

In addition to the Control File and Name File, GSFLOW input files include those necessary for active MODFLOW packages, PRMS Parameter and Data Files, and optionally, PRMS CBH Files. The time periods specified in the Data and CBH Files that are used for the restart simulation can be different from those used for the spin-up simulation as long as the simulation time period for the restart simulation (as specified by control parameters start_time and end_time in the Control File) is included in the files. As with previous versions of GSFLOW, the Data and CBH Files can specify a longer time period than the simulation time period.

The four types of information required for a PRMSonly or GSFLOW restart simulation are (1) simulation control options and PRMS modules (such as the simulation time period and selectable PRMS modules), (2) model input 
parameters, (3) forcing data and stresses, and (4) calculated antecedent conditions from the spin-up simulation.

Because a spin-up simulation represents conditions for a particular day and set of simulation options, the PRMS Initial Conditions File typically is used as a continuation from that day beginning on the day subsequent to the last day of the spin-up simulation, with the identical set of simulation options. However, to provide flexibility in the simulation of hydrologic processes and output of results, the restart option allows some PRMS options to differ between the spin-up and restart simulations. The code verifies that an Initial Conditions File used for a restart simulation was generated by a spin-up simulation using compatible PRMS modules and computation options as specified in the Control File. By compatible, it is meant that the computation of some hydrologic processes and summary output have multiple options, some of which can differ between the spin-up and restart simulations. However, results using different computation options for a spin-up and restart-simulation combination likely will not be the same as those for a continuous simulation for the same time period. The simulation, input, and output options that can differ between spin-up and restart simulations are the following:

- potential evapotranspiration can be computed using any combination of modules potet_jh (JensenHaise method), potet_hamon (Hamon method), and climate_hru (predistributed values based on any user-defined distribution method) as specified by control parameter et_module. However, if the potet_pan (Pan evaporation method) module is used for a spin-up simulation, it must be used for a restart simulation;

- precipitation distribution can be computed using any combination of modules precip_1sta (specified adjustment factors using data from a precipitation measurement station), precip_laps (a computed lapse rate based on data from two precipitation measurement stations at different altitudes), precip_dist2 (specified lapse rates and the inverse of the square of the distance between the centroid of the HRU and the location and data from multiple precipitation measurement stations), and climate_hru (predistributed based on any user-defined distribution method) as specified by control parameter precip_module. However, if the xyz_dist (a three-dimensional, multiple-linear regression method using data from multiple precipitation measurement stations) module is used for a spinup simulation, it must be used for a restart simulation;

- solar radiation can be computed using any combination of modules ccsol rad (cloud-cover method) and ddsolrad (degree-day method), as specified by control parameter solrad_module; and

- output summary options can be different for any combination of modules subbasin (summary of select states and fluxes by subbasin), map_results (output files of selected states and fluxes for use as input to other software at specified temporal and spatial resolutions), and write_climate_hru (output CBH Files based on specified climate distribution options), and for the Statistic Variable File and Animation File options.

The temperature-distribution module, as specified by control parameter temp_module, cannot be changed between the spin-up and restart simulations. Also, the number of measured values for each type of data (temperature, precipitation, streamflow, solar radiation, pan evaporation, and snow depth), as specified in the PRMS Data and optional CBH Files, cannot be changed. That is, the dimensions for these data types cannot be changed; if they are, an error message is issued and execution stops. The column order of measured data values in a Data File can change (although changing the order is not recommended), but the number of measurement stations for any data type cannot change. The column order in CBH Files cannot change because these columns are tied to the HRU identification numbers. However, the values and time period in the Data and CBH Files can be changed. For example, the Data and CBH Files input to a restart simulation can specify only the time period and data values required by the restart simulation and values used in the spin-up simulation are not required. Thus, a Data and CBH File used in a restart simulation could be small in comparison to, and have values not included in, a spin-up Data and CBH File. The simulation time period, which is specified by control parameters start_time and end_time, cannot be longer than, and must be included within, the time period specified in the Data or optional CBH Files. If the specified time period does not meet these requirements, an error message is issued and execution stops.

All of the parameters specified in the Control File and Parameter Files are read and used for a restart simulation for PRMS-only and GSFLOW modes. Any of these values can differ between the spin-up and restart simulations except for computation options as described above. Also, rediscretization of the model domain should not be done after the spin-up simulation. Therefore, discretization parameters should be the same for spin-up and restart simulations, such as elevation, slope, aspect, latitude, type, and area of HRUs; mapping between HRUs and finite-difference cells; and cascades. Some HRU-characteristic and discretization parameters, such as fraction of impervious area, canopy density, and plant cover type, also should not be changed because they can create incompatibilities between the antecedent conditions and the restart simulation. Six parameters specified in the Parameter File that are associated with initial water-content states are ignored for a restart simulation. These parameters are the initial water content of the capillary reservoir (soil_moist_init), recharge zone of the capillary reservoir (soil_rechr_init), snowpack (snowpack_init), gravity reservoir (ssstor_init), groundwater reservoir (gwstor_init), and the initial density of the snowpack (den_init) (Markstrom and others, 2015). However, empirical coefficients and calibration parameters such as interflow, potential evapotranspiration, solar-radiation 
equation coefficients, and temperature and precipitation adjustment factors, can differ. Results using different parameter values for a pair of spin-up and restart simulations likely will not be the same as a continuous simulation for the same time period. Some discretization dimensions and parameters are checked for consistency between the PRMS Initial Conditions and Parameter Files, including the number of HRUs, lakes, and intersections between HRUs and finite-difference cells; the simulation mode; and whether or not cascades are active. If these differ between the spin-up and restart simulations, an error message is issued and execution stops.

Similar to PRMS, some input values and options for MODFLOW can change between spin-up and restart simulations. However, input related to model spatial discretization must be consistent between spin-up and restart simulations. Hydraulic properties of aquifers, including hydraulic conductivity and aquifer storage, can change between spin-up and restart simulations. However, significant changes in hydraulic properties may cause problems in the solution due to incompatible initial hydraulic conditions and aquifer properties. The magnitude of change in aquifer properties that is suitable for a restart simulation depends on the problem, and users should make such changes with caution. The total number of streams, lakes, and wells in a simulation must not change between spin-up and restart simulations. However, as with a continuous MODFLOW simulation, streams, lakes, and wells can be made active during a restart simulation. A stream segment can be made active by changing segment connectivity to other segments or lakes and by changing the streambed hydraulic conductivity to be nonzero. A lake can be made active by connecting inflowing and outflowing segments and by changing the values of the LKARR variable in the Lake Package input file (Merritt and Konikow, 2000). Wells can be made active by specifying nonzero pumping rates and, for wells simulated by the MODFLOW Multi-Node Well version 2 (MNW2) Package (Konikow and others, 2009), by specifying nonzero values for the cell-to-well leakance parameter.

The new restart option for GSFLOW consists of two steps-writing antecedent-conditions files for a spin-up simulation (step 1) and reading antecedent-conditions files for a restart simulation (step 2). The values specified in the Control File and MODFLOW Name File that are directly related to the restart option are described for this two-step process below; all other values specified in the Control File and Name File that are required for a particular simulation are described in Markstrom and others (2008) and with each new release of GSFLOW (http://water.usgs.gov/ogw/gsflow/).

\section{Step 1-Run the Spin-Up Simulation}

(a) Specify two control parameters in the Control File for the spin-up simulation that define the simulation start time (start_time) and end time (end_time). These parameters must be specified for both the spin-up and restart simulations. An example of how to specify parameters start_time and end time in the Control File is:

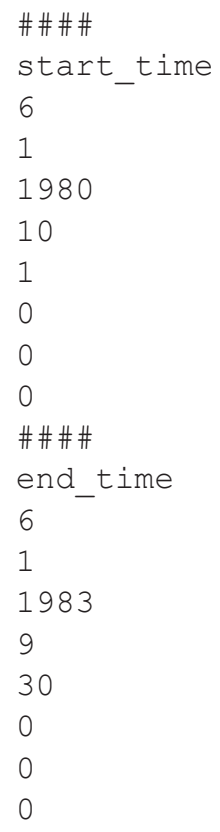

(b) This step depends on the simulation mode.

- For PRMS-only and GSFLOW simulation modes, specify control parameters save_vars_to_file and var_ save_file in the Control File. Parameter save_vars_ to_file is specified equal to 1 . Parameter var_save_file specifies the pathname of the PRMS Initial Conditions File that will be written at the end of the simulation. An example of how this parameter is specified in the Control File is:

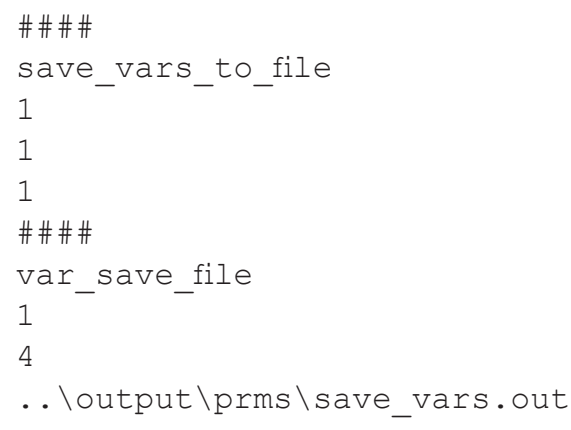

- For MODFLOW-only and GSFLOW simulation modes, specify control parameter save_vars_to_file and the date corresponding to the first time step of the first transient stress period of the MODFLOW model (modflow_time_zero) in the Control file and the IWRT file type in the MODFLOW Name File. Parameter save_vars_to_file is specified equal to 1 as described above. This indicates that the MODFLOW Restart Write File is written to the file specified by the IWRT file type. An example of how to specify an IWRT file type in the Name File is

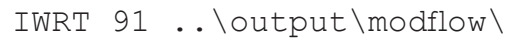


An example of how to specify parameter modflow_time_ zero in the Control File is

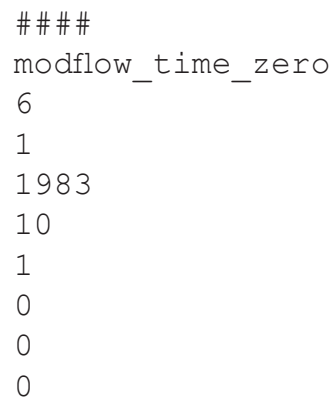

\section{Step 2-Run the Restart Simulation}

(a) Once the simulation that writes the antecedent conditions is completed, a subsequent restart simulation can be executed by specifying control parameter start_time to the day following the end of the spin-up simulation. For example, if control parameter end_time for the spin-up simulation was specified as September 30, 1983, then start time for the restart simulation must be specified as October 1, 1983.

(b) This step depends on the simulation mode.

- For PRMS-only and GSFLOW simulation modes, specify control parameters init_vars_from_file and var_init_file in the Control File. Parameter init_vars_ from_file is specified equal to 1 . Parameter var_init_ file specifies the pathname of the PRMS Initial Conditions File that will be read at the start of the restart simulation. This file is written by the spin-up simulation. An example of how to specify these parameters in the Control File for the restart simulation is:

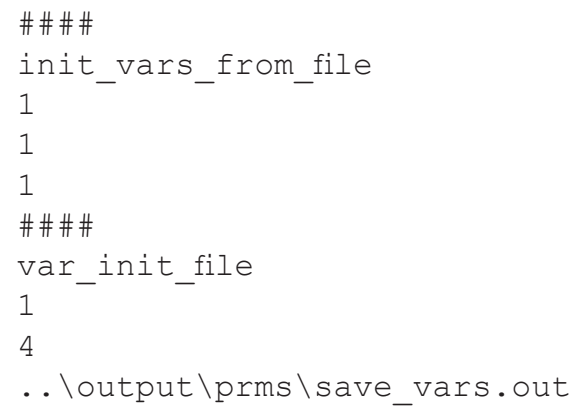

- For MODFLOW-only and GSFLOW simulation modes, specify control parameter init_vars_from_file and modflow_time_zero in the Control file and the IRED file type in the MODFLOW Name File. Parameter init_vars_from_file is specified to equal 1. This indicates that the MODFLOW Restart Read File will be read from the file specified by the IRED file type. This file is written by the spin-up simulation. If the MODFLOW stress-period and boundary-condition inputs are different for the spin-up and restart simulations, then control parameter modflow_time_zero may be specified with different values in the Control File for each simulation. An example of how to specify an IRED file type in the Name File for the restart simulation is

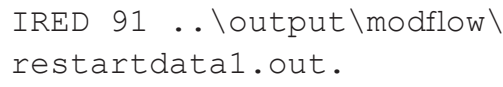

PRMS and (or) MODFLOW antecedent-conditions files can be read and written during a single simulation when both control parameters init_vars_from_file and save_vars_to_file are specified equal to 1 in the Control File. First, the file specified by var_init_file in the Control File and (or) the file specified by the IRED file type specified in the MODFLOW Name File are read as the antecedent conditions for the first day of the restart simulation (that is, the day following the last day of the spin-up simulation). Second, the file specified by var_save_file in the Control File and (or) the file specified by the IWRT file type in the Name File are written at the end of the restart simulation. These files can then be used as antecedent conditions for subsequent, compatible, restart simulations. For PRMS-only and GSFLOW simulation modes, the pathnames specified for the control parameters var_save_file and save_vars_to_file could be the same for the spin-up and restart simulations. This should only be done when the PRMS Initial Conditions File is not needed for any additional restart simulations because it is overwritten at the end of the simulation. For MODFLOW-only and GSFLOW simulation modes, the pathnames and unit numbers specified by the IRED and IWRT file types must be different if the reading and writing of restart files occur during the same simulation.

For MODFLOW-only and GSFLOW simulation modes, the input file containing antecedent conditions for MODFLOW can be specified in two ways. Typically, a spinup simulation will use starting heads that have been specified in the Basic (BAS) Package input file using variable STRT, as is done for standard MODFLOW simulations. In some cases, however, the user may want to use antecedent conditions for a spin-up simulation that have been generated from a previous spin-up simulation and saved to a MODFLOW Restart Write File specified by the IWRT file type in the Name File. The spin-up simulation used to write this Restart Write File might have been written by a restart simulation. In these cases, the user will specify the pathname of the previously written MODFLOW Restart Write File as the Restart Read File (file type IRED).

When antecedent conditions are read from a Restart Read File, starting heads that have been specified in the BAS input file are ignored and the steady-state stress periods will be skipped if the restart simulation was specified to start with a steady-state stress period. Note that file unit numbers, file locations, and file names for IRED and IWRT follow the standard protocol for files defined in the Name file (see Markstrom and others, 2008, p. 177). The MODFLOW antecedentconditions files are written to and read from unformatted files; however, the unformatted specification does not need to be explicitly defined in the Name file. 


\section{Tests of the Restart Option}

The restart option was tested with several GSFLOW application models, including those for the Sagehen Creek watershed, California (Markstrom and others, 2008); Incline Creek watershed, Nevada (Huntington and Niswonger, 2012); Trout Lake watershed, Wisconsin (Hunt and others, 2013); Lake Tahoe watershed, California and Nevada (Huntington and others, 2013); Santa Rosa Plain watershed, California (Woolfenden and Nishikawa, 2014); and Walker Lake watershed, Nevada (Niswonger and others, 2014). Results from tests with the Sagehen Creek watershed and Lake Tahoe watershed models are described herein (the locations of the Sagehen Creek and Lake Tahoe watersheds are provided in this report; the locations of the other test models are not shown in this report). Both watersheds are located in the northern Sierra Nevada region.

The general approach that was used to test the restart option is illustrated in figure 2. In an initial (or base) simulation, each model is run for the total simulation time period (fig. $2 A$ ); this is referred to as the continuous simulation. The total simulation time period then is divided into multiple time periods in which the calculated results required as antecedent conditions are saved at the end of each simulation for use as antecedent conditions for the subsequent restart simulations (fig. 2B); this set of simulations is referred to as the hindcast simulations. The restart simulations are referred to as hindcast because each simulation uses observed (that is, historical) climate data and other stresses instead of forecasted stresses.
Results from the hindcast simulations were compared to those generated by the continuous simulation to verify that changes made to the GSFLOW code for the restart option work as intended; results calculated at each time step from the set of hindcast simulations should be close in value to those calculated by the continuous simulation.

\section{Sagehen Creek Watershed Model}

The restart option was first tested with a modified version of the GSFLOW model of the Sagehen Creek watershed that is described in Markstrom and others (2008) and distributed with each GSFLOW release (http://water.usgs.gov/ogw/ gsflow/). This watershed is located on the eastern slope of the northern Sierra Nevada Range near Truckee, California (fig. 3). A number of changes were made to the model for the testing. First, the source of climate data (air temperature and precipitation) and approach used to specify these climate data in the model were changed. Previous versions of the model were based on climate data available from an NWS cooperative climate station in the Sagehen Creek watershed and a Natural Resources Conservation Service (NRCS) snow telemetry (SNOTEL) station in the vicinity of the watershed (Markstrom and others, 2008). Simulation results reported here use areally averaged minimum and maximum air temperature and precipitation output from the Daymet climate model (http://daymet.ornl.gov/; Thornton and others, 1997, 1999), as supported by the National Aeronautics and Space Administration (NASA). The Daymet gridded datasets were retrieved

\section{A. Continuous mode}

\section{Start}

simulation simulation

\section{B. Restart mode}

Start

simulations

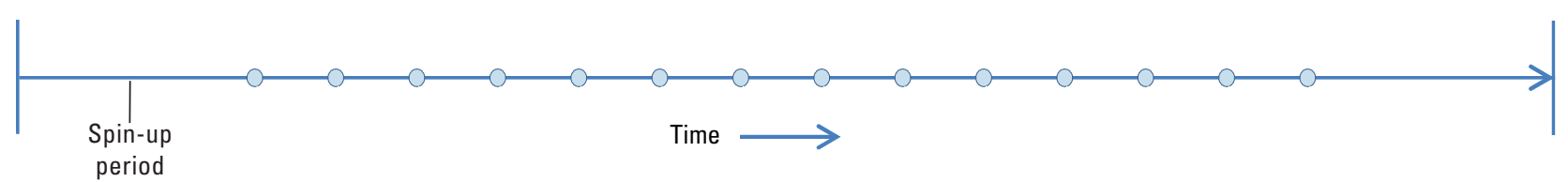

EXPLANATION

Restart times

Figure 2. Approach used to test the GSFLOW restart option. $A$, Continuous simulation mode and $B$, restart simulation mode. 
and formatted for use in the model with the USGS GeoData Portal (http://cida.usgs.gov/gdp/). Each of the downloaded climate datasets were then converted to the $\mathrm{CBH}$ input-file structure for use in the continuous and hindcast simulations. The format and use of CBH Files is described in the file Climate_hru.pdf distributed with each GSFLOW release (http://water.usgs.gov/ogw/gsflow/). An additional change that was made for some of the test simulations was the introduction of several hypothetical wells that were simulated by use of the MNW2 Package (Konikow and others, 2009); these wells were added for the purpose of testing the MNW2 functionality with the restart option. The locations of these wells are shown in figure 3. Because these simulations were done for testing purposes only, no recalibration of the model was done as part of the testing process.

Test simulations were done with the MODFLOWonly, PRMS-only, and GSFLOW simulation modes for the period October 1, 1980, through September 30, 1996. This period spans a wide range of hydrologic conditions in the watershed and therefore provides a good basis for evaluating a wide range of simulation results. The period October 1, 1980, through January 30, 1984, is used here to illustrate comparisons between the results of the continuous and restart simulations. Seven restart related parameters are specified in the Control File for the continuous and hindcast simulations. An initial continuous simulation was done for the entire period. This simulation then was followed by a set of 15 hindcast simulations. The first (or spin-up) hindcast simulation covered the period October 1, 1980 (specified by parameter start_time), through September 1, 1983 (parameter end_time); parameter modflow_time_zero was specified as October 1, 1980, for the first time step of the first transient stress period (fig. 4). Note that a 3-year spin-up period may not be of sufficient length to account for transient groundwater conditions for many hydrologic systems, but is sufficient for this test example. Parameter init_vars_from_file is specified equal to 0 for this simulation, which indicates that a PRMS Initial Conditions File will not be read (and the value specified for parameter var_init_file is ignored if specified because antecedent conditions are not read for this spin-up simulation). PRMS-calculated results for September 1, 1983, are saved as antecedent conditions for the next hindcast simulation in the file .. / output/prms/prms_ic_1 by specification of parameter var_save_file, and parameter save_vars_to_file is specified equal to 1 (fig. 4). The MODFLOW Name File for the first hindcast simulation (fig. $5 \mathrm{~A}$ ) does not include file type IRED; initial groundwater heads for this simulation are read from the MODFLOW BAS File. MODFLOW-calculated results for use in the second hindcast simulation are saved to file . / / output/prms/restartdatal.out, which is specified by file type IWRT in the Name File (fig. $5 A$ ).

The spin-up simulation was followed by 14 additional simulations in which antecedent conditions for each simulation were read from files saved at the end of the previous simulation. The 14 simulations start on September 2, 1983, and run through January 30,1984 . Of the 14 simulations, 13 have a 7-day simulation time period, whereas the last simulation has a 60-day time period. Selected input for the Control File for the first of these 14 simulations is shown on figure 6. Parameters start_time and end_time are specified as September 2, 1983, and September 8, 1983, respectively, and modflow_time_zero again is specified as October 1, 1980, for the first time step of the first transient stress period (fig. 6). Because parameter init vars_from_file is specified equal to 1, PRMS antecedent conditions are read from file.. / output/prms/prms_ic_1, as specified by parameter var_init_file. Results calculated by PRMS and GSFLOW modules for September 8, 1983, are written to the PRMS Initial Conditions File .. / output/prms/prms_ic_2, as specified by parameter var_save_file (fig. 6); file .. / output/prms/prms_ic_2 is then read as antecedent conditions for the third hindcast simulation. The MODFLOW Name File for the second hindcast simulation (fig. $5 B$ ) includes both file types IRED and IWRT. Initial conditions for the simulation are read from file .. / output/prms/restartdatal. out, which was generated in the spin-up hindcast simulation, and written to file../output/prms/restartdata2. out at the end of the simulation.

Selected GSFLOW simulation-mode results for the continuous simulation were compared to those for each hindcast simulation. Comparisons between the continuous and hindcast simulations for more than 60 output variables tracked during the testing process indicate that the restart option is working as intended and producing very small errors, generally on the order of 0.001 to 0.0001 percent difference between the continuous and hindcast simulations, and no difference for variables unrelated to groundwater and surface-water interactions such as snowpack water equivalent. Discrepancies between the continuous and restart simulations possibly are caused by differences in the precision of variables stored in computer memory that are used to make intermediate calculations during convergence of the nonlinear iterative solution procedures for groundwater and surface-water interactions in the GSFLOW simulation mode. Results for the continuous and hindcast simulations were identical for tests in which the model was run in either MODFLOW-only or PRMS-only simulation modes.

The results for one of the GSFLOW-mode simulations are illustrated in figure 7, which shows simulated streamflow at the outflow point of the watershed, storage in the saturated zone, and storage in the unsaturated zone for August 28 through December 22, 1983. The results shown on figure $7 \mathrm{~A}$ indicate that the percent difference between streamflow calculated by the continuous and hindcast simulations is generally less than 0.005 , with a maximum error of about 0.011 on September 9. The results shown in figures $7 B$ and $7 C$ indicate that the percent difference between the continuous and hindcast simulations for both saturated-zone and unsaturated-zone storage are very low, generally less than 0.00005 . 


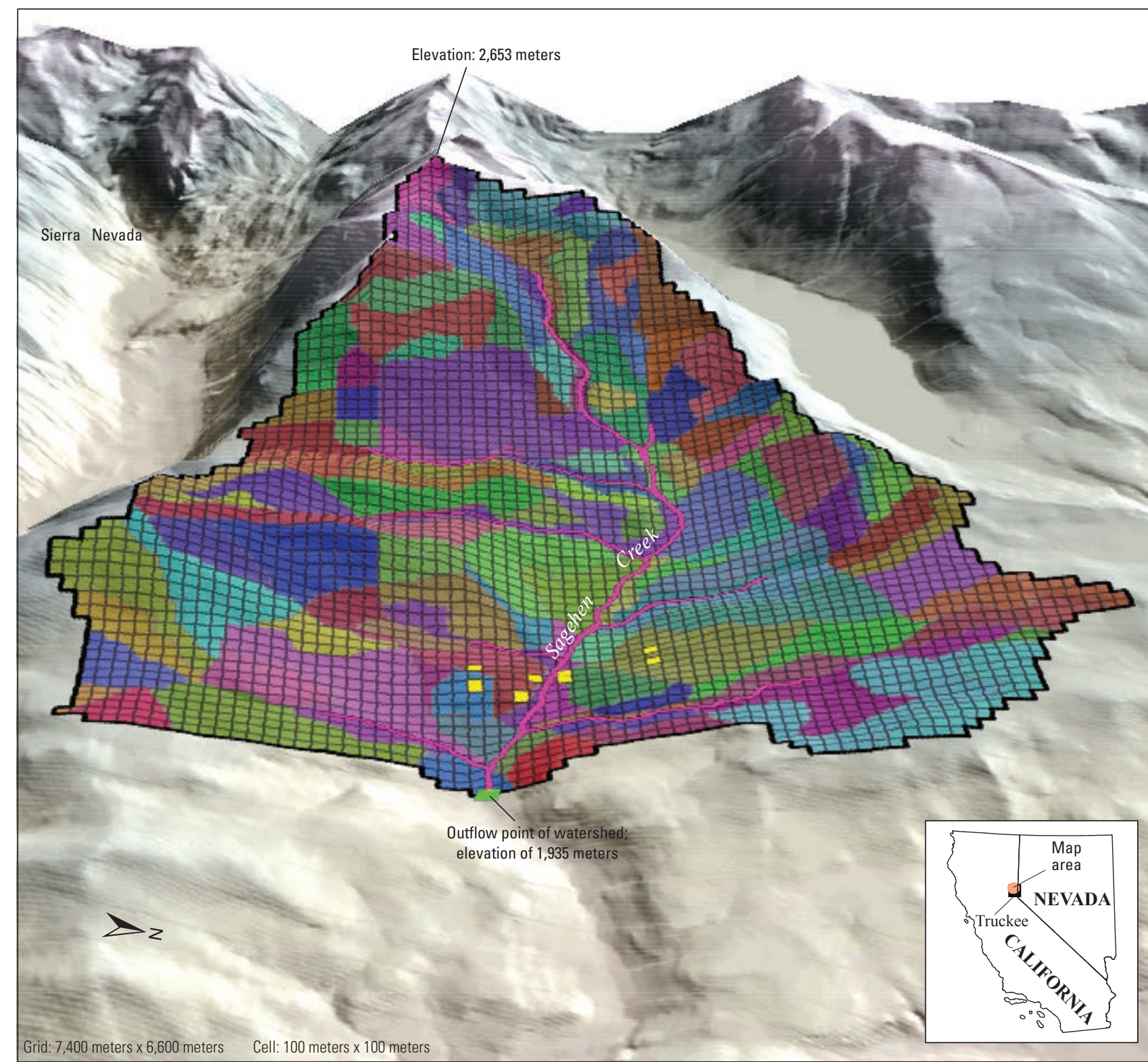

Shaded-relief base from U.S. Geological Survey

10-meter National Elevation Dataset, 2012

EXPLANATION

Universal Transverse Mercator projection, Zone 11

North American Datum of 1983

Illumination from the northwestat $45^{\circ}$

Altitude is 6,300 meters above land surface

Viewing angle is $24^{\circ}$ (from latitude 39.46 , longitude -120.09

Vertical exaggeration is $2 x$

\section{EXPLANATION}

Hydrologic response unit

Finite-difference grid

Cell with hypothetical well

Model boundary

Figure 3. Model boundary of the Sagehen Creek watershed near Truckee, California. 


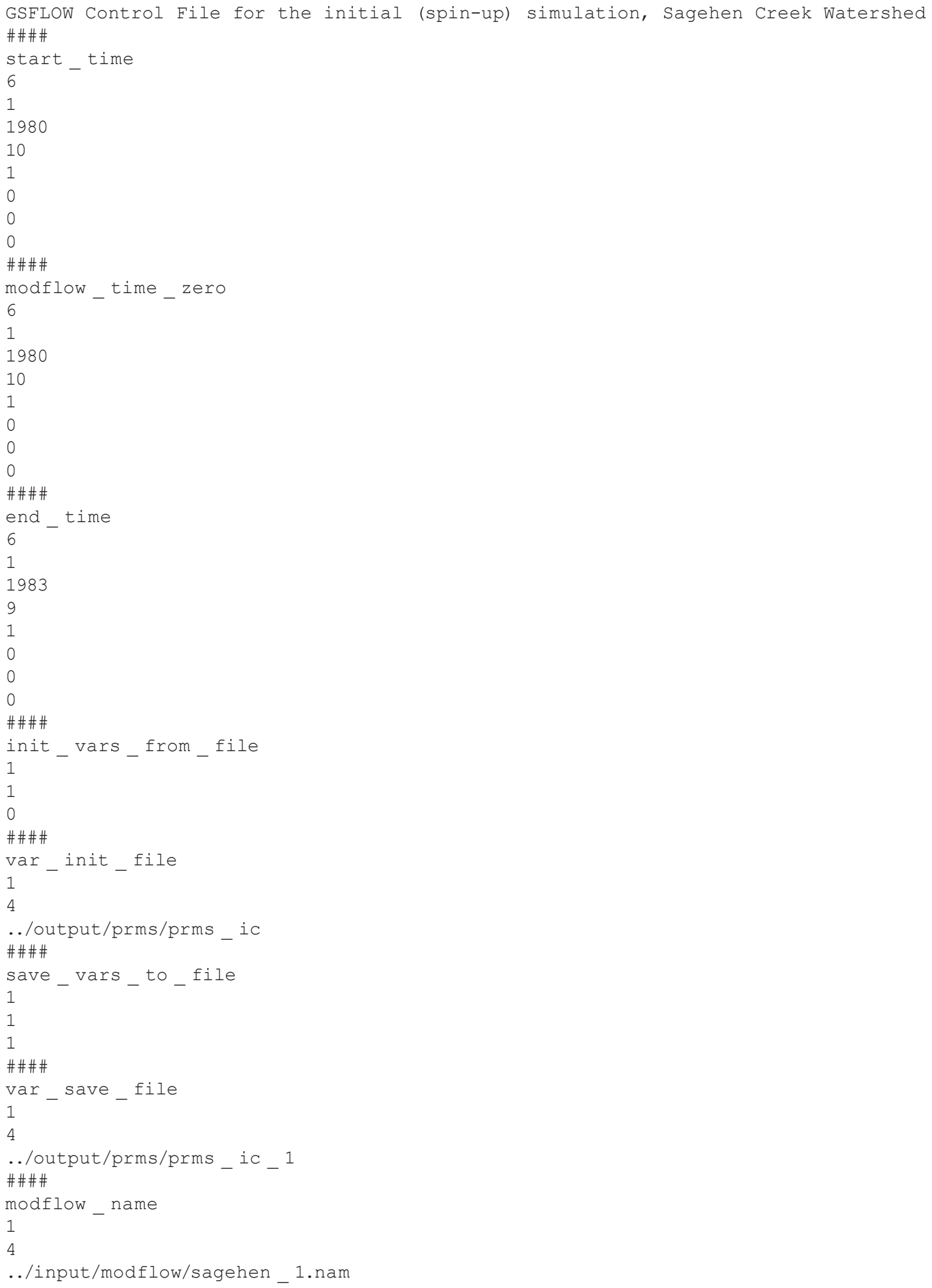

Figure 4. Part of the Control File for the first (or spin-up) hindcast simulation for tests with the GSFLOW model of the Sagehen Creek watershed near Truckee, California. 
A

\begin{tabular}{|c|c|c|}
\hline LIST & 26 & ..loutput/modflow/sagehen_-1.list \\
\hline AS 6 & 8 & ..lnput/modt 1 ow/sagehen.bas \\
\hline & 9 & ../input/modflow/sagehen.oc \\
\hline LS & 11 & ../input/modflow/sagehen.dis \\
\hline PW & 12 & ../input/modflow/sagehen.upw \\
\hline & 13 & ../input/modflow/sagehen.nwt \\
\hline $\mathrm{zf}$ & 14 & ...input/modflow/sagehen.uzf \\
\hline Er & 15 & ...input/modflow/sagehen.sfr \\
\hline ge & 16 & ../input/modflow/sagehen.gag \\
\hline VRT & 91 & ../input/modflow/restartdatal.out \\
\hline ata & 58 & ..loutput/modflow/head_sagehen_1.out \\
\hline ata & 65 & ...loutput/modflow/uz1_sagehen__1.out \\
\hline & 66 & ..loutput/modflow/uz2_sagehen__.out \\
\hline ta & 67 & ../output/modflow/uz3_sagehen_- 1. out \\
\hline & 68 & ..loutput/modflow/uz4_sagehen__.out \\
\hline & 80 & ../output/modflow/sagehen_sfrseg13_1.out \\
\hline & 81 & ...loutput/modflow/sagehen_sfrseg15_1.out \\
\hline & 82 & ../output/modflow/sagehen_sfrseg16_1.out \\
\hline & 83 & ../output/modflow/sagehen_sfrseg17_ 1. out \\
\hline
\end{tabular}

$\boldsymbol{B}$

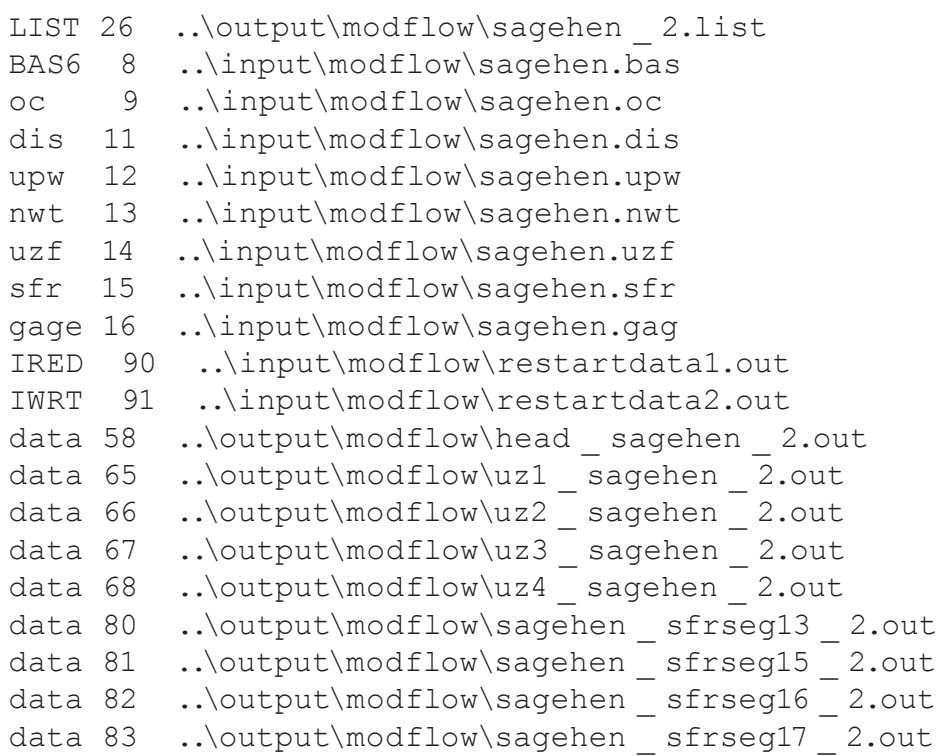

Figure 5. MODFLOW Name Files for two hindcast simulations with the GSFLOW model of the Sagehen Creek watershed near Truckee, California. $A$, First (or spin-up) simulation and $B$, second hindcast simulation. 


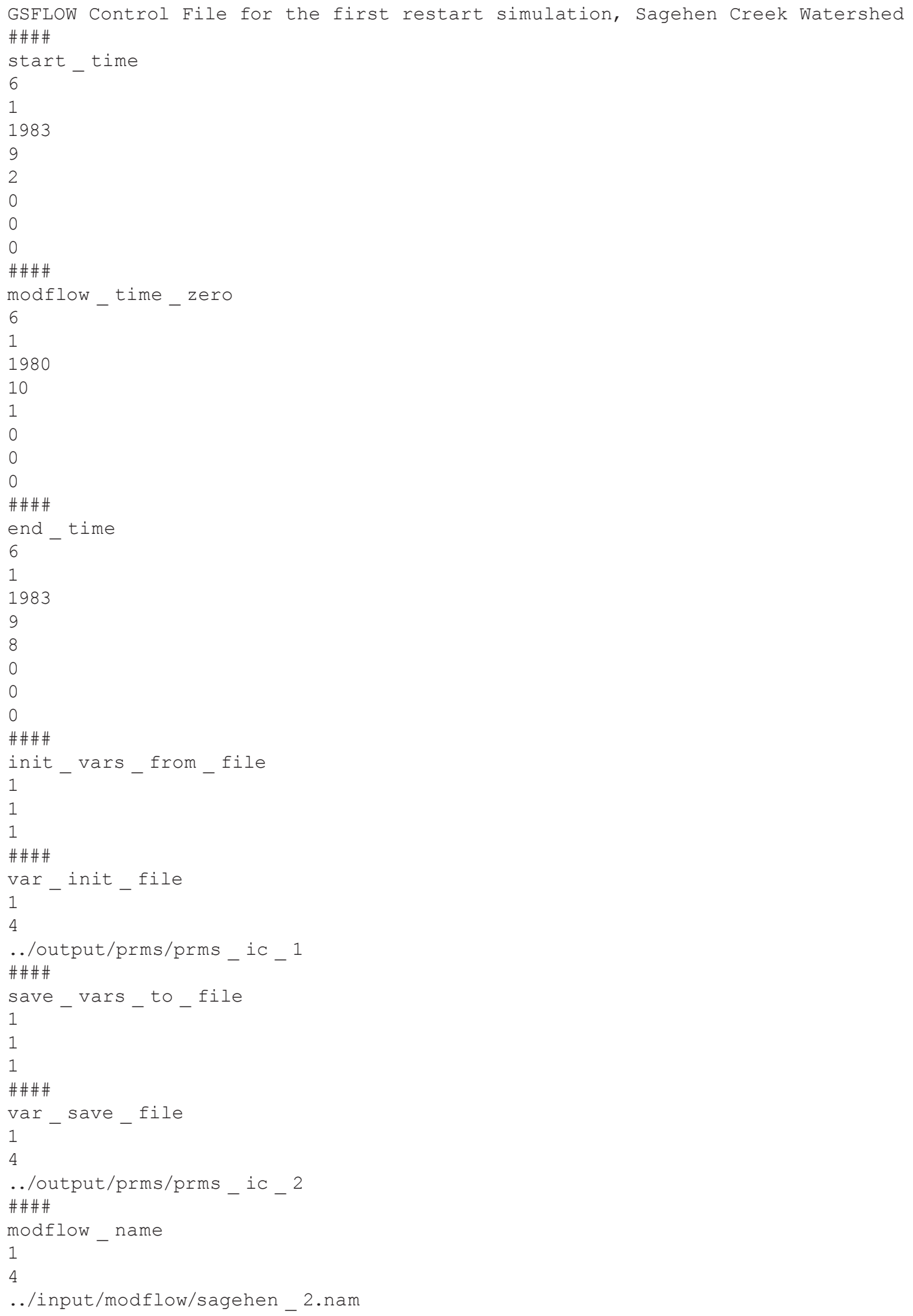

Figure 6. Part of the GSFLOW Control File for the second hindcast simulation for tests with the GSFLOW model of the Sagehen Creek watershed near Truckee, California. 

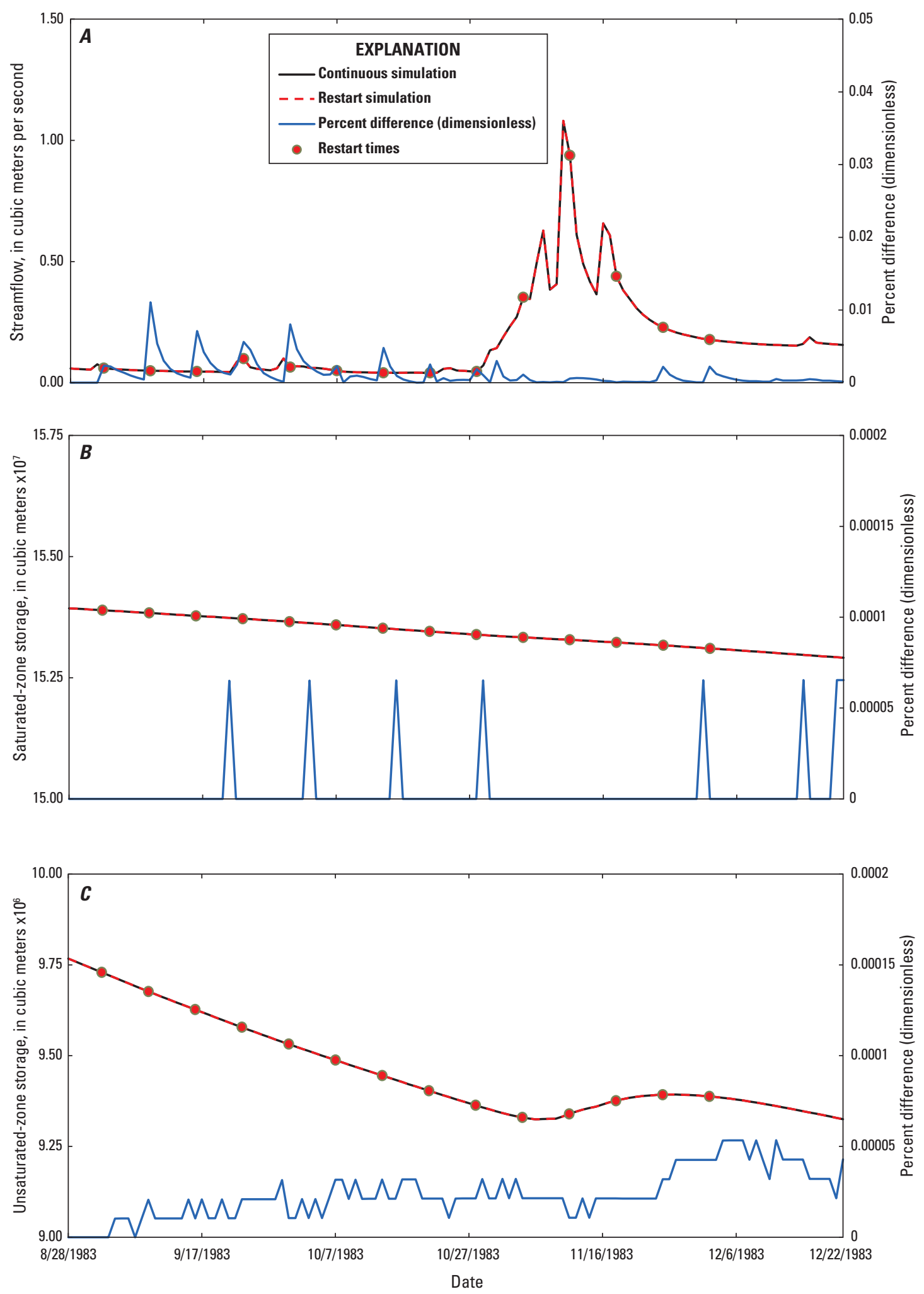

Figure 7. Results for the continuous and hindcast simulations for tests with the GSFLOW model of the Sagehen Creek watershed near Truckee, California. A, Simulated streamflow for Sagehen Creek at outflow of the watershed; $B$, simulated storage in the saturated zone; and $C$, simulated storage in the unsaturated zone. [Percent difference is calculated as $100 \times((Q c-Q r) / Q c)$, where $Q c$ is the simulated value for the continuous simulation and $Q r$ is the simulated value for the hindcast simulation.] 


\section{Lake Tahoe Watershed Model}

The Lake Tahoe watershed straddles the border between California and Nevada west of Carson City, Nevada (fig. 8). The Lake Tahoe watershed GSFLOW model is documented in Huntington and others (2013) and is used here as a test of the restart option for simulations that include the Lake (LAK7) Package (Merritt and Konikow, 2000); there are seven lakes in the model that are represented with the LAK7 Package. The watershed was discretized into $300 \mathrm{~m}$ by $300 \mathrm{~m}$ grid cells and all of the major streams flowing into the lake were represented in the model (fig. 8). Additional details about the construction of the model can be found in Huntington and others (2013).

The general approach used to test the restart option with the Lake Tahoe model was the same as that used for the Sagehen Creek model (fig. 2). An initial continuous simulation was made for the period October 1, 1980, through January 30, 1984. The continuous simulation then was followed by 15 hindcast simulations. As with the Sagehen Creek watershed example, the first (or spin-up) hindcast simulation time period

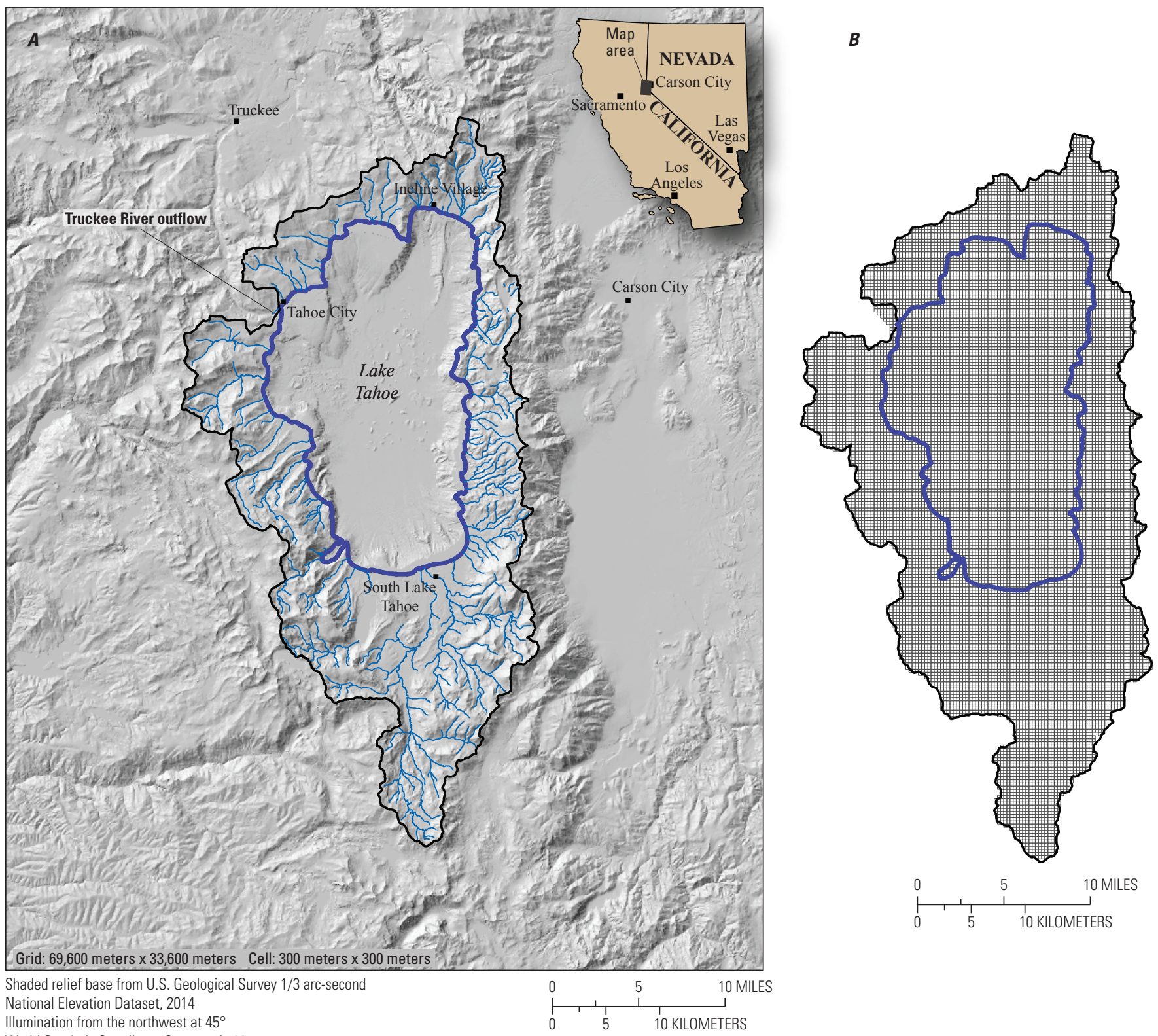

World Geodetic Coordinate System of 1984

\section{EXPLANATION}

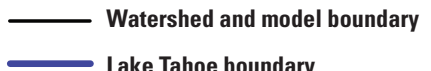

Lake Tahoe boundary

Figure 8. Area of the GSFLOW model of the Lake Tahoe watershed on the border between California and Nevada. A, Lake Tahoe watershed and $B$, surface and groundwater discretization used for GSFLOW model. 
was October 1, 1980, through September 1, 1983. This was followed by a set of 14 hindcast simulations, the first of which begins on September 2, 1983, and the last on December 2, 1983. All but the last hindcast simulation has a 7-day simulation time period; the last simulation was run for a 60-day time period.

Selected GSFLOW simulation-mode results from the continuous simulation were compared to those for each hindcast simulation. Comparisons between the continuous and hindcast simulations for more than 60 output variables tracked during the testing process indicate that the restart option is working as intended and producing very small errors, generally on the order of 0.0001 to 0.00001 percent difference between the continuous and hindcast simulations.

Results from one of the GSFLOW-mode tests for the period August 1 through December 22, 1983, are shown in figure 9. The top graph (fig. 9A) shows simulated streamflow exiting Lake Tahoe. The results indicate that the percent difference between streamflow calculated by the continuous and hindcast models is less than $10 \times 10^{-9}$, which is the minimum precision for single-precision computations. Differences in the simulated streamflow between the continuous and hindcast simulations for the Lake Tahoe watershed model are much smaller than those for the Sagehen Creek watershed model. This is because streamflow exiting Lake Tahoe is only dependent on lake stage, whereas streamflow exiting the Sagehen Creek watershed is dependent on many hydrologic conditions in the model (for example, overland surface runoff and groundwater flow to streams) resulting in a greater number of sources of error. The percent difference between the continuous and hindcast simulations was generally about 0.001 for the saturated-zone and unsaturated-zone storage, with a maximum of about 0.004 for the saturated-zone storage (fig. $9 B$ ) and 0.14 for the unsaturated-zone storage (fig. $9 C$ ). The errors for saturated-zone and unsaturated-zone storage values are not correlated to the restart times and, thus, these errors are most likely related to cumulative rounding errors of intermediate variables used within the code.
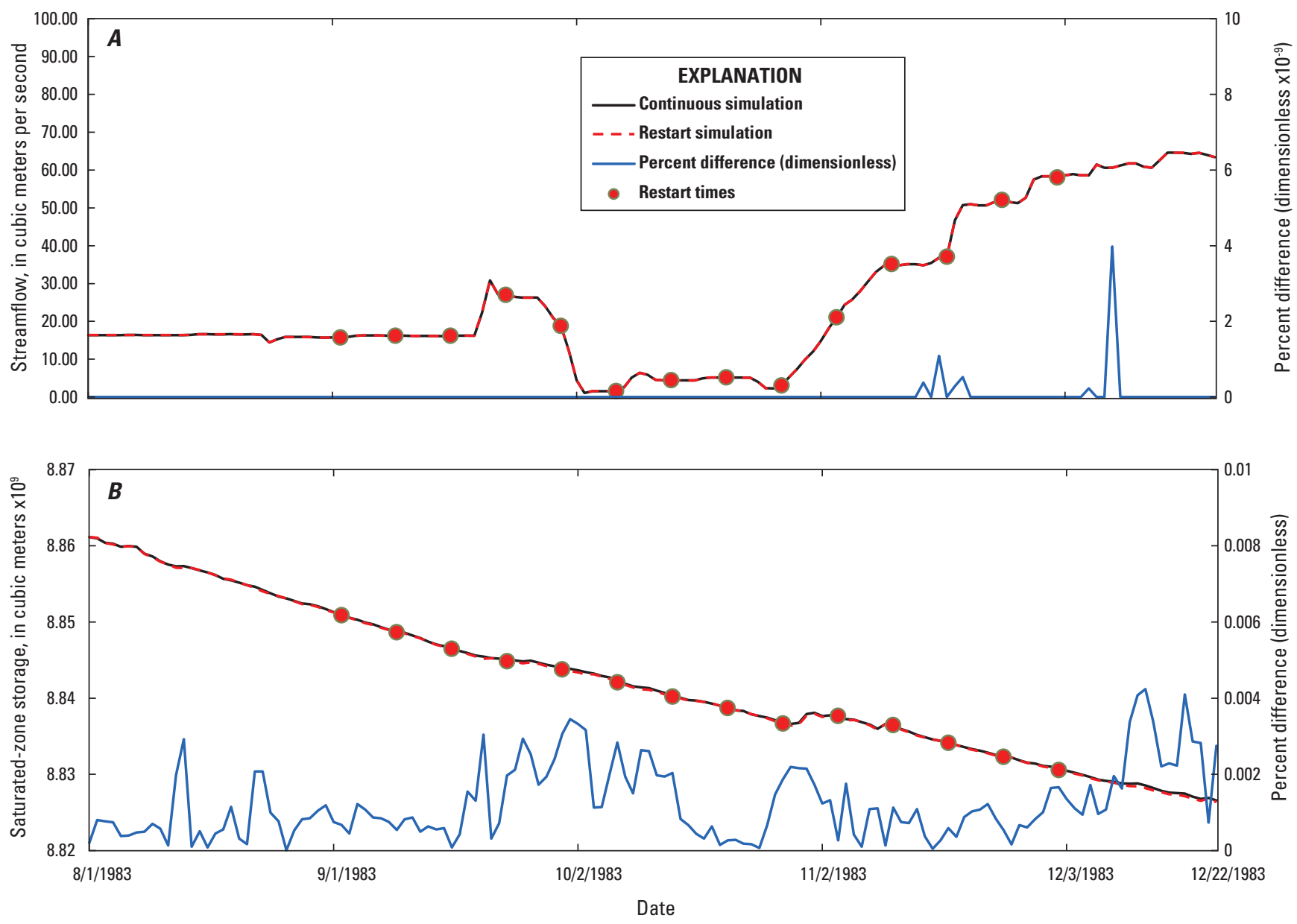

Figure 9. Results for the continuous and hindcast simulations for tests with the GSFLOW model of the Lake Tahoe watershed on the border between California and Nevada. $A$, Simulated streamflow at outflow of Lake Tahoe and $B$, simulated storage in the saturated zone. Percent difference is calculated as $100 \times((Q c-Q r) / Q c)$, where $Q c$ is the simulated value for the continuous simulation and $Q r$ is the simulated value for the hindcast simulation. 

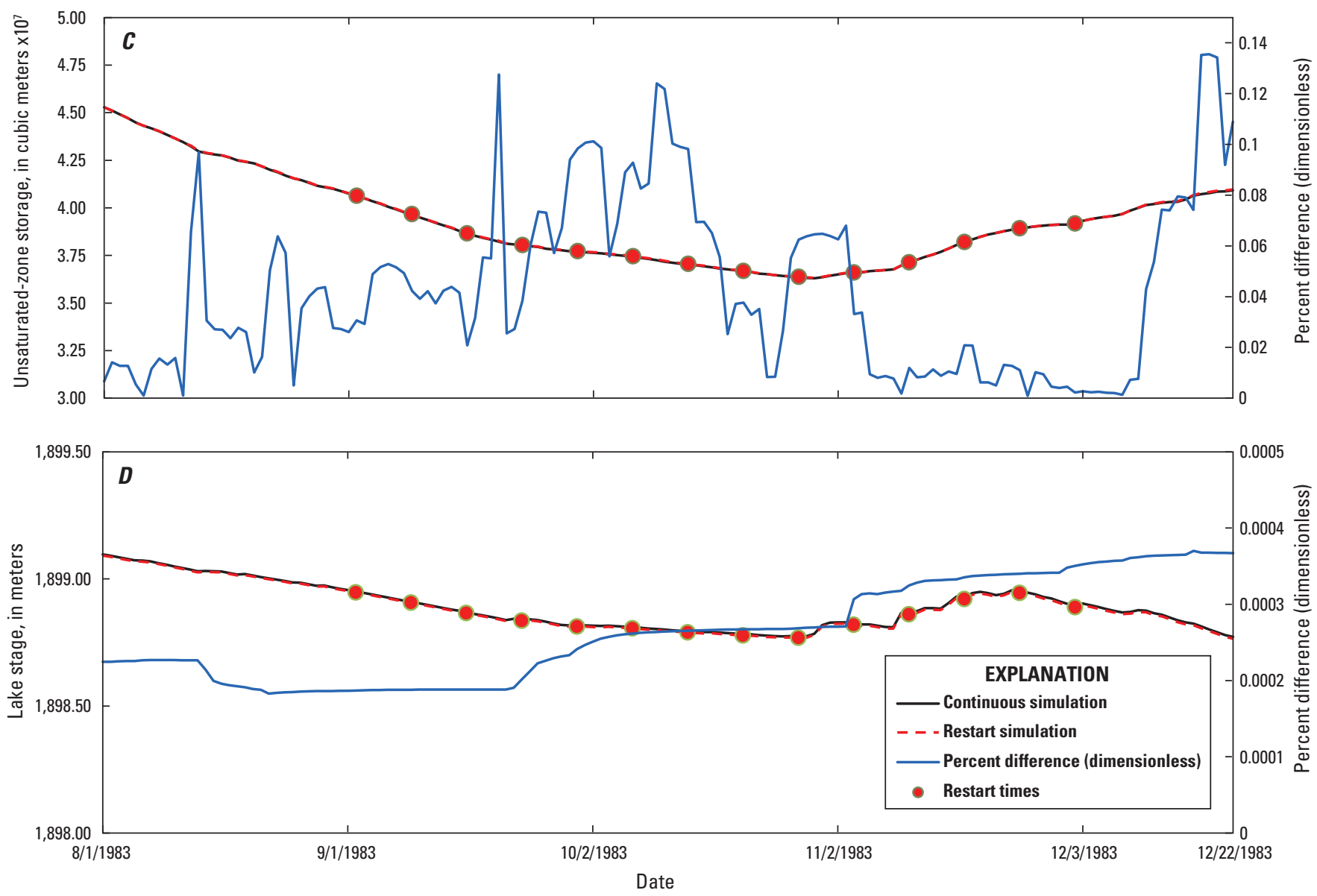

Figure 9. Results for the continuous and hindcast simulations for tests with the GSFLOW model of the Lake Tahoe watershed on the border between California and Nevada. $C$, Simulated storage in the unsaturated zone and $D$, stage of Lake Tahoe. Percent difference is calculated as $100 \times((Q c-Q r) / Q c)$, where $Q c$ is the simulated value for the continuous simulation and $Q r$ is the simulated value for the hindcast simulation.-Continued

\section{Summary}

The Groundwater and Surface-Water Flow (GSFLOW) model is a numerical, hydrologic simulation code that can be used to improve the understanding and management of groundwater/surface-water interactions at the scale of a watershed. GSFLOW is an integration of the USGS Precipitation-Runoff Modeling System (PRMS) and USGS Modular Groundwater-Flow Model (MODFLOW). A new restart option was developed for GSFLOW to provide a means to (1) calculate antecedent conditions (also referred to as initial conditions) that account for the hydrologic memory within a simulated watershed for a specified spin-up time period; (2) write all simulation results to files that are required to initiate a restart simulation; and (3) read the contents of those files as antecedent conditions for any number of subsequent simulations. All three GSFLOW simulation modes (MODFLOW-only, PRMS-only, and GSFLOW) can be executed with the restart option. The restart option was developed in collaboration with the National Weather Service as part of the Integrated Water Resources Science and Services Partnership. The primary focus for the development of the restart option was to support medium-range (7- to 14-day) forecasts of low streamflow conditions made by the National Weather Service for critical water-supply basins in which groundwater plays an important role. However, the restart option is useful for any modeling activity that requires repeated simulations that use a common set of antecedent conditions, such as ensemble simulations, model calibration, and sensitivity analysis.

Use of the restart option can greatly reduce the time required to execute GSFLOW simulations because a spin-up period is not required for each simulation. A spin-up period was required for previous versions of GSFLOW to establish antecedent conditions for the model that reflect equilibrium hydrologic conditions and hydrologic memory of periodic climatic conditions and other stresses. With this new version of GSFLOW, results from a spin-up simulation can be saved 
and used in any number of subsequent restart simulations, thus avoiding the need to run a spin-up period for every simulation. Previous versions of GSFLOW have had some capability to save model results for use as antecedent conditions in subsequent simulations and to specify initial values for some model states. However, these previous capabilities were not comprehensive or easy to use.

This report describes changes made to the GSFLOW code and input files to develop the restart option. Test simulations are presented using two previously documented GSFLOW models for the Sagehen Creek watershed, California, and the Lake Tahoe watershed, California and Nevada. Test simulations that include a series of 15 restart simulations indicate that the restart option provides nearly identical results to those produced for a continuous simulation for the same time period.

\section{References Cited}

Day, G.N., 1985, Extended streamflow forecasting using NWSRFS: Journal of Water Resources Planning and Management, v. 111, no. 2, p. 157-170.

Harbaugh, A.W., 2005, MODFLOW-2005, the U.S. Geological Survey modular ground-water model-The groundwater flow process: U.S. Geological Survey Techniques and Methods, book 6, chap. A16, [variously paged]. [Also available at http://pubs.usgs.gov/tm/2005/tm6A16/.]

Henson, W.R., Medina, R.L., Mayers, C.J., Niswonger, R.G., and Regan, R.S., 2013, CRT_Cascade routing tool to define and visualize flow paths for grid-based watershed models: U.S. Geological Survey Techniques and Methods, book 6, chap. D2, 28 p., accessed October 28, 2014, at http://pubs.usgs.gov/tm/tm6d2/.

Hunt, R.J., Walker, J.F., Selbig, W.R., Westenbroek, S.M., and Regan, R.S., 2013, Simulation of climate-change effects on streamflow, lake water budgets, and stream temperature using GSFLOW and SNTEMP, Trout Lake watershed, Wisconsin: U.S. Geological Survey Scientific Investigations Report 2013-5159, 118 p., accessed October 28, 2014, at http://pubs.usgs.gov/sir/2013/5159/.

Huntington, J.L., and Niswonger, R.N., 2012, Role of surfacewater and groundwater interactions on projected summertime streamflow in snow dominated regions - An integrated modeling approach: Water Resources Research, v. 48, no. 11, paper W11524, 20 p., accessed October 28, 2014, at http://dx.doi.org/10.1029/2012WR012319.
Huntington, J.L., and Niswonger, R.N., Rajagopal, Seshadri, Zhang, Yong, Gardner, Murphy, Morton, C.G., Reeves, D.M., McGraw, David, and Pohll, G.M., 2013, Integrated hydrologic modeling of Lake Tahoe and Martis Valley mountain block and alluvial systems, Nevada and California, in Proceedings of the MODFLOW and More 2013 Conference-Translating Science Into Practice, June 2-5, 2013, Golden, Colo.: Golden, Colo., International Ground Water Modeling Center, Colorado School of Mines, 5 p.

Konikow, L.F., Hornberger, G.Z., Halford, K.J., and Hanson, R.T., 2009, Revised multi-node well (MNW2) package for MODFLOW ground-water flow model: U.S. Geological Survey Techniques and Methods, book 6, chap. A30, 67 p. [Also available at http://pubs.usgs.gov/tm/tm6a30/.]

Leavesley, G.H., Lichty, R.W., Troutman, B.M., and Saindon, L.G., 1983, Precipitation-runoff modeling systemUser's manual: U.S. Geological Survey Water-Resources Investigations Report 83-4238, 207 p. [Also available at http://pubs.usgs.gov/wri/1983/4238/report.pdf.]

Leavesley, G.H., Markstrom, S.L., Viger, R.J., and Hay, L.E., 2005, USGS modular modeling system (MMS) - Precipitation-runoff modeling system (PRMS) MMS_PRMS, in Singh, V.P., and Frevert, D.K., eds., Watershed models: Boca Raton, Fla., CRC Press, p. 159-177.

Markstrom, S.L., Niswonger, R.G., Regan, R.S., Prudic, D.E., and Barlow, P.M., 2008, GSFLOW-Coupled ground-water and surface-water flow model based on the integration of the precipitation-runoff modeling system (PRMS) and the modular ground-water flow model (MODFLOW-2005): U.S. Geological Survey Techniques and Methods, book 6, chap. D1, 240 p. [Also available at http://pubs.usgs.gov/tm/ tm6d1/.]

Markstrom, S.L., Regan, R.S., Hay, L.E., Viger, R.J., Webb, R.M.T, Payn, R.A., and LaFontaine, J.H., 2015, PRMS-IV, the Precipitation-Runoff Modeling System, version 4: U.S. Geological Survey Techniques and Methods, book 6, chap. B7, 158 p., http://dx.doi.org/10.3133/tm6B7.

Merritt, M.L., and Konikow, L.F., 2000, Documentation of a computer program to simulate lake-aquifer interaction using the MODFLOW ground-water flow model and the MOC3D solute-transport model: U.S. Geological Survey WaterResources Investigations Report 00-4167, 146 p.

Niswonger, R.G., Allander, K.K., and Jeton, A.E., 2014, Collaborative modelling and integrated decision support system analysis of a developed terminal lake basin: Journal of Hydrology, v. 517, p. 521-537, accessed October 28, 2014, at http://dx.doi.org/10.1016/j.jhydrol.2014.05.043. 
Niswonger, R.G., Panday, Sorab, Ibaraki, Motomu, 2011, MODFLOW-NWT, A Newton formulation for MODFLOW-2005: U.S. Geological Survey Techniques and Methods, book 6, chap. A37, 44 p. [Also available at http://pubs.usgs.gov/tm/tm6a37/.]

Niswonger, R.G., and Prudic, D.E., 2005, Documentation of the streamflow-routing (SFR2) package to include unsaturated flow beneath streams-A modification to SFR1: U.S. Geological Survey Techniques and Methods, book 6, chap. A13, 48 p. [Also available at http://pubs.usgs.gov/tm/2006/ $\operatorname{tm} 6 \mathrm{~A} 13 /$.

Niswonger, R.G., Prudic, D.E., Regan, R.S., 2006, Documentation of the Unsaturated-Zone Flow (UZF1) Package for modeling unsaturated flow between the land surface and the water table with MODFLOW-2005: U.S. Geological Survey Techniques and Methods, book 6, chap. A19, 74 p. [Also available at http://pubs.usgs.gov/tm/2006/tm6a19/.]
Thornton, P.E., and Running, S.W., 1999, An improved algorithm for estimating incident daily solar radiation from measurements of temperature, humidity, and precipitation: Agricultural and Forest Meteorology, v. 93, no. 4, p. 211-228.

Thornton, P.E., Running, S.W., and White, M.A., 1997, Generating surfaces of daily meteorological variables over large regions of complex terrain: Journal of Hydrology, v. 190, no. 3-4, p. 214-251.

Woolfenden, L.R., and Nishikawa, Tracy, eds., 2014, Simulation of groundwater and surface-water resources of the Santa Rosa Plain watershed, Sonoma County, California: U.S. Geological Survey Scientific Investigations Report 2014-5052, 258 p., accessed October 28, 2014, at http://dx.doi.org/10.3133/sir20145052. 

For more information, please contact: U.S. Geological Survey Office of Groundwater 411 National Center Reston, VA 20192

Telephone: (703) 648-5001 Internet: http://water.usgs.gov/ogw/

Publishing support by:

The Pembroke and Rolla Publishing Service Centers 
